\title{
Otra universidad es posible
}

http://doi.org/10.15359/ree.17-3.1

\section{Another University is Possible}

\author{
Luis Guillermo Barrantes Montero' \\ Escuela de Literatura y Ciencias del Lenguaje \\ Universidad Nacional \\ Heredia, Costa Rica \\ luisba66@yahoo.es
}

Recibido 18 de abril de 2013 • Corregido 16 de julio de 2013 • Aceptado 31 de julio de 2013

\begin{abstract}
Resumen. Se plantea un modo de ser y hacer universidad desde un nuevo paradigma, el cual deriva de las exigencias de las sociedades del siglo XXI. Luego de una breve sinopsis de los modelos tradicionales de universidad -con lo que se pretende ilustrar, de manera diacrónica, el estado de la situación de las universidades hasta llegar al modelo imperante en la actualidad-, se propone un paradigma que aún se encuentra en ciernes: el paso de la uni-versidad a la multi-diversidad, mediante la integración del conocimiento, el desarrollo del pensamiento crítico y la democratización del saber, con miras al bien común.
\end{abstract}

Palabras claves. Universidad, paradigma, conocimiento, educación superior.

Abstract. This paper proposes a way to be a University and to work as a University based on a new paradigm that responds to the demands of the 21st century society. After a brief overview of the traditional university models -as a way to illustrate, diachronically, the state of the situation of universities up to the currently prevailing model- a paradigm that is still in process is proposed: the transition from uni-versity to multi-diversity, through the integration of knowledge, development of critical thinking, and democratization of knowledge in order to reach common good.

Keywords. University, paradigm, knowledge, higher education.

1 Posee una Maestría Profesional en la Enseñanza del Inglés, por la Universidad de Costa Rica (2006). Cuenta además con una Licenciatura en Traducción Inglés-Español, por la Universidad Nacional, Costa Rica (1996), una Licenciatura en Teología, por la Universidad Francisco Marroquín, Guatemala (1992) y un Bachillerato en Filosofía, por la Universidad Francisco Marroquín, Guatemala (1989). Durante diecinueve años se ha desempeñado como docente de inglés y de español como segunda lengua y actualmente coordina el Departamento de cursos de servicio en la Universidad Nacional, Costa Rica. Ha realizado ponencias en congresos internacionales y varios de sus artículos y ponencias han sido publicados en revistas como Educare y Letras, ambas de la Universidad Nacional. 
URL: http://www.una.ac.cr/educare

CORREO: educare@una.cr
La utopía está en el horizonte. Me acerco dos pasos, ella se aleja dos pasos. Camino diez pasos y el horizonte se corre diez pasos más allá. Por mucho que yo camine, nunca la alcanzaré. ¿Para qué sirve la utopía? Para eso sirve: para caminar.

Fernando Birri

La humanidad del siglo XXI se reclama a sí misma la necesidad de revisar los paradigmas con que se conduce cada una de las manifestaciones culturales que forman parte de ella (Marín, 2007). La crítica y autocrítica, la de-construcción y re-construcción de los principios y modos de actuar son vitales en el tiempo presente para la convivencia y para la sobrevivencia misma de la especie (Pérez, 2010). Sobre todo, y dada su mayor influencia y expansión planetaria, la cosmovisión conocida como mundo occidental posee, proporcionalmente, una tarea mucho más ardua con respecto a su cuota de responsabilidad ante estos desafíos.

Si bien, en algunas culturas los derroteros a seguir son marcados por la autoridad depositada en consejos de ancianos, monarcas o liderazgos políticos o religiosos de diversa índole, Occidente ha optado por las vías democráticas (con los consabidos matices que cada localidad le impone a este concepto) para la toma de decisiones en cuanto a temas trascendentales (Mejía y Jiménez, 2005). Esta parece haber demostrado ser una manera óptima para que se conduzcan las sociedades en las que sus individuos tienen a su disposición los recursos educativos y los medios de información que les permiten, no solo enterarse, sino también incidir, en alguna medida, en las decisiones que toman sus autoridades.

Por ese mismo talante occidental de acceso al conocimiento $y$, en consecuencia, a la posibilidad de contribuir en la desmitificación y en las transformaciones que, de forma continua, se engendran en sus sociedades, han ido apareciendo clamores por nuevas utopías y atisbos de paradigmas alternativos, difíciles de manifestar en otros contextos políticos. Entre esos clamores se presentan, tan solo a manera de ejemplo, los siguientes: La Fageda: Otra empresa es posible (Segarra, 2011); Otra psicología es posible (Marín, 2006); Otra televisión es posible (2010); Otro mundo es posible (Santos, citado por Dale y Robertson, 2004); Otro cristianismo es posible (Lanaers, 2006).

Este trabajo consiste en esbozar la propuesta de que también otra universidad es posible. La relevancia del tema obedece que a que la imagen de universidad, en el momento actual, se enmarca dentro de determinados paradigmas que es importante someter a revisión (Campillo y Sáez, 2013).

Se inicia con una breve pincelada a lo que ha sido la historia de la institución universitaria, para ubicarla en cuanto a las razones que han dado origen a los distintos modelos y énfasis de estas. En un segundo momento, se plantea la situación de crisis que afrontan los modelos de universidad tradicionales para ubicar, posteriormente, la propuesta de un nuevo paradigma universitario que satisfaga la sed de conocimiento emancipador al cual aspiran las sociedades en los albores del tercer milenio, y que "aún está por inventarse" (Macherey, 2011 citado por Ema, García, Arribas y Cano, 2013). Luego de esa propuesta se delinean dos derivaciones de ese nuevo

2 Fernando Birri, citado por Eduardo Galeano y estos a su vez citados por Mejía (2008, p. 6). Ver referencia. 
paradigma: uno es la integración del saber, como el gran desafío de la nueva universidad y, el otro, la construcción del bien común como principio orientador para la vida en sociedad.

\section{Síntesis de los modelos de universidad}

A continuación se presenta una tabla que resume los modelos de universidad más representativos que se han presentado a lo largo de la historia de la cultura occidental. Cada modelo es ubicado en su época y lugar de aparición, junto con la coyuntura histórica en que se originó y el propósito de las universidades en cada uno de ellos.

Tabla

Modelos de universidad más representativos a lo largo de la historia de la cultura occidental

\begin{tabular}{|c|c|c|c|}
\hline Modelo de universidad & Época & Coyunturas históricas & Propósito de las universidades \\
\hline $\begin{array}{l}\text { Universidad medieval } \\
\text { (Gilson, 1965) }\end{array}$ & Siglos XI- XIV. & $\begin{array}{l}\text { * Obras clásicas de la antigüedad } \\
\text { son recogidas por amanuenses } \\
\text { benedictinos. } \\
\text { * Disputas entre el papado y los reyes. } \\
\text { Tradición dominica (aristotélica) } \\
\text { * Tradición franciscana (platónica) } \\
\text { * Énfasis en lo "universal" de la } \\
\text { universidad, el dogmatismo y el } \\
\text { poder pontificio }\end{array}$ & $\begin{array}{l}\text { * Salermo (s. XI: énfasis en medicina) } \\
\text { * Bolonia (s. XI: énfasis en derecho } \\
\text { civil. El poder estaba en manos de los } \\
\text { estudiantes) } \\
\text { * París (s. XII: Poder conjunto de } \\
\text { estudiantes y maestros. Cuenta con la } \\
\text { protección del papado). } \\
\text { * Oxford y Cambridge (s.XII. énfasis } \\
\text { en el Aristóteles empírico -no el } \\
\text { metafísico-y desarrollo de las } \\
\text { ciencias naturales). } \\
\text { * Studium Generale (Roma s. XIII) } \\
\text { * Salamanca (España s.XIII) }\end{array}$ \\
\hline $\begin{array}{l}\text { La universidad en los } \\
\text { períodos renacentista, } \\
\text { humanista, reformista y } \\
\text { contra-reformista }\end{array}$ & $\begin{array}{l}\text { Siglos XV, XVI y } \\
\text { XVII }\end{array}$ & $\begin{array}{l}\text { * Énfasis en el interés particular de } \\
\text { los estados nacientes. } \\
\text { * Mengua la escolástica y surge el } \\
\text { humanismo. } \\
\text { * Movimientos de reforma y contra- } \\
\text { reforma }\end{array}$ & $\begin{array}{l}\text { * La tradición neo-platónica (Ficino) } \\
\text { Ileva a la concepción antropocéntrica } \\
\text { del movimiento humanista y a la } \\
\text { generación del concepto de dignidad } \\
\text { del hombre (Pico della Mirandola) } \\
\text { * La universidad debe ayudar a resolver } \\
\text { los problemas del Estado (Ilustración) } \\
\text { * Durante la reforma se introduce } \\
\text { la crítica al dogma y al papado } \\
\text { (Universidad de Wittenberg). } \\
\text { * La contra-reforma encuentra en } \\
\text { los colegios jesuíticos -de corte } \\
\text { humanista- un replanteamiento } \\
\text { al modelo escolástico, ya en } \\
\text { decadencia. }\end{array}$ \\
\hline
\end{tabular}

continúa... 
URL: http://www.una.ac.cr/educare

CORREO: educare@una.cr

\begin{tabular}{lcc}
\multicolumn{1}{c}{ Modelo de universidad } & Época & Coyunturas históricas \\
\hline La universidad según & Siglos XVIII y XIX & $*$ La Revolución Francesa requiere \\
el modelo napoleónico & de la formación de ciudadanos que \\
(francés) & sirvan a la administración del Estado \\
& $*$ Napoleón entiende la Universidad \\
& como un bastión militar al servicio \\
& del Estado
\end{tabular}

Propósito de las universidades

* La Universidad de Francia suplanta a todas las demás en esa nación y desde ella se dirige todo el quehacer de la educación superior francesa. La universidad se identifica con los intereses del Estado y se dedica a formar castas de profesionales que sirvan adecuadamente a los requerimientos de la nación.

\begin{tabular}{|c|c|c|c|}
\hline $\begin{array}{l}\text { La universidad según el } \\
\text { modelo humboldtiano } \\
\text { (alemán) }\end{array}$ & Siglo XIX & $\begin{array}{l}\text { Whilhelm von Humboldt persuade } \\
\text { al rey de Prusia para crear un Centro } \\
\text { Universitario que interese a los jóvenes } \\
\text { en la ciencia como parte de su vida } \\
\text { diaria. }\end{array}$ & $\begin{array}{l}\text { * La Universidad de Berlín busca } \\
\text { demostrar cómo se genera el } \\
\text { conocimiento (ideas de los filósofos } \\
\text { Schelling, Fichte y Sleiermacher). } \\
\text { * Desde entonces, las universidades } \\
\text { alemanas aparejan en su cometido la } \\
\text { docencia y la investigación. }\end{array}$ \\
\hline
\end{tabular}

La universidad según Desde el s. XII El modelo británico es de corte liberal. * El propósito es la formación del el modelo anglosajón No tiene un énfasis investigativo (Oxford-Cambridge) (alemán) ni profesional (francés), sino de cultivo del ser humano. ser humano lo más ampliamente posible, sin limitarse a lo investigativo (alemán) ni a la formación de profesionales.
* Cardenal John Henry Newman: La educación liberal procura formar un hábito de la mente que dure toda la vida.* $^{*}$

\begin{tabular}{|c|c|c|c|}
\hline $\begin{array}{l}\text { Modelos } \\
\text { latinoamericanistas de } \\
\text { universidad: } \\
\text { Andrés Bello, José } \\
\text { Vasconcelos y el } \\
\text { Movimiento de Córdoba }\end{array}$ & $\begin{array}{l}\text { Andrés Bello: s. } \\
\text { XIX } \\
\text { José Vasconcelos } \\
\text { s. XX } \\
\text { Movimiento de } \\
\text { Córdoba } \\
\text { s. XX }\end{array}$ & $\begin{array}{l}\text { Las universidades aún no asumían el } \\
\text { papel docente sino que se centraban } \\
\text { en la investigación, según el modelo } \\
\text { humboldtiano. En 1920, Vasconcelos } \\
\text { asume la rectoría de la Universidad de } \\
\text { México. A inicios del s. XX en Córdoba, } \\
\text { Argentina, la emergente clase media } \\
\text { y el proletariado industrial se alzan en } \\
\text { contra del dominio de las } \\
\text { universidades por parte de las } \\
\text { oligarquías y el clero. }\end{array}$ & $\begin{array}{l}\text { * Bello: La universidad debe regir la } \\
\text { enseñanza nacional con énfasis en las } \\
\text { ciencias y las artes. } \\
\text { * Vasconcelos: La universidad debe } \\
\text { ser autónoma y libre. Expresión de } \\
\text { la nueva raza latinoamericana libre y } \\
\text { original. } \\
\text { * Movimiento de Córdoba: Reclamo } \\
\text { de la autonomía universitaria y de } \\
\text { que los temas universitarios sean } \\
\text { importantes para el Estado. }\end{array}$ \\
\hline $\begin{array}{l}\text { Modelo neo- liberal } \\
\text { actual de universidad }\end{array}$ & 1985 al presente & $\begin{array}{l}\text { Declive del bloque soviético y } \\
\text { expansión mundial del capitalismo } \\
\text { económico financiero mediante la } \\
\text { llamada corriente globalizadora. }\end{array}$ & \\
\hline
\end{tabular}

Notas: Para el presente resumen se han tomado como referencia: Jaramillo, 2011 y Moncada, 2008.

${ }^{*}$ Ver Newman, J. H (2007). 


\section{La crisis de los paradigmas tradicionales de universidad}

Los modelos de universidad recopilados y presentados brevísimamente en la tabla anterior, sin duda no incluyen algunos otros patrones que han aparecido a lo largo de la historia. No obstante, se ha procurado hacer mención, al menos, de los más trascendentes o representativos. La finalidad no es otra que mostrar, mediante una pincelada, sus principios fundamentales y las coyunturas históricas en que surgieron que, si bien cada cual habrá podido responder de forma adecuada a determinadas circunstancias de lugar y tiempo, no tienen por qué seguir considerándose válidas e inmutables cuando y dondequiera se les intente emular.

Veamos algunas razones de por qué esos modelos se encuentran en crisis. Al hacer referencia a "crisis" no se pretende afirmar que algunos de ellos no sean aún exitosos, sobre todo los que siguen una corriente pragmática; lo que se acusa más bien es que, tal y como están planteados, producen más desconcierto que seguridad y soluciones para las generaciones de este tercer milenio. Según Moncada (2008), en el caso específico de América Latina, se requiere de un modelo de universidad que corresponda a los paradigmas de esta época, es decir, el desarrollo humano sustentable, la cultura de paz y la educación permanente.

En primer lugar, la raigambre religiosa, desde la que se erigió la universidad en sus albores medievales, hace tiempo ya que cedió lugar a una concepción laica y secular en la mayoría de las naciones. La influencia de la religión cristiana institucionalizada ha ido decreciendo en proporción al nivel educativo y económico de las sociedades. Paralelamente, la educación y, en general, el acceso a la información se están poniendo al alcance del individuo común. Se debe advertir, sin embargo, que hoy en día las grandes cadenas informativas multinacionales y sus aliados, los anunciantes comerciales, han tomado el lugar que en la antigüedad ostentó la religión institucional ("Otra televisión es posible", 2010). El saber que un día se difundió con concomitantes mensajes religiosos, en la actualidad conlleva otro tipo de mensajes, muchos de corte hedonista, de consumo y de culto al momento presente; es decir, con características propias de las sociedades postmodernas.

En segundo lugar, los modelos de universidad que sucedieron al Medioevo y al Renacimiento, como por ejemplo los humanistas, los investigativos, intelectualistas, neoliberales e incluso los que han abogado por una autonomía frente al Estado y las entidades financieras internacionales, se han mantenido, de todos modos, ligados a la institucionalidad. En ellos comporta rigor científico aquello que haya sido producido, ratificado o avalado por alguna instancia institucional, reconocida, a su vez, por las autoridades competentes del país y del extranjero. De igual modo, el individuo adquiere determinado rango profesional cuando le es otorgado un título o diploma emitido o reconocido por una institución de educación superior. Ante ello, Hessel (2010) nos invita a indignarnos para transformar "la dictadura profesional instaurada a imagen al estilo de los estados fascistas".

En la actualidad no es posible ejercer un oficio considerado "profesional", si no se está debidamente agremiado al respectivo colegio y, por lo tanto, si no se está en posesión de un título universitario "a como haya lugar" (Haba, 2002, p. 81). En este sentido, la ciencia y el derecho 
URL: http://www.una.ac.cr/educare

CORREO: educare@una.cr

han ido de la mano en procura de normar las relaciones laborales y la responsabilidad en la prestación de los servicios, pero también han contribuido a ensanchar la brecha social como consecuencia de la disparidad de oportunidades para los ciudadanos.

Si bien, la convivencia en sociedad demanda un control de calidad de los bienes y servicios que se tranzan y un equilibrio entre los derechos y deberes de las partes negociantes, no es menos cierto que también existen saberes ancestrales que han sido invisibilizados, muchos de los cuales han sido "hurtados" (Gómez, 2008) y patentados como propios por corporaciones multinacionales, siempre con el respaldo de algún profesional académico y de autoridades de gobierno. No se debe dejar de mencionar que también hay informaciones de diversa índole, que no se dan a conocer al público, pues lesionan los intereses de algún grupo o sector económico "Otra televisión es posible" (2010). Esta maraña de poder y exclusión ha corrompido desde sus inicios el saber institucionalizado en cualesquiera de sus formas.

Las sociedades no occidentales (y las no occidentalizadas) reclaman, por una parte, el desdén de sus saberes milenarios y, por otro, la toma de decisiones con trascendencia planetaria por parte de los centros hegemónicos de occidente. De nuevo, la sensibilidad postmoderna del siglo XXI cuestiona esa forma de saber y de producción del conocimiento como la "única" posible. La actitud "rebelde" o irreverente de las generaciones nuevas no es otra cosa que su reacción ante un orden que no encaja con su cosmovisión. Como lo afirma Zevallos Aguilar (2002, citado por Paravicino, 2003) con referencia al contexto específico peruano: "A las manifestaciones de una nueva realidad modelada por la aplicación del modelo neoliberal... correspondía el desembalse de una nueva sensibilidad que surge en un tiempo de tránsito de la modernidad a la postmodernidad ..." (p. 277).

En tercer lugar, como en todo ámbito del quehacer humano, el tema del financiamiento económico está presente. Por una parte, las universidades que fueron creadas como entidades públicas y con financiamiento estatal se ven ahora en dificultades para obtener los fondos que les corresponden ya que, los gobiernos de turno, simpatizantes en mayor o menor medida del capital transnacional y el neo-liberalismo, privilegian las carreras universitarias y los proyectos de investigación que aporten capital humano profesional y, por supuesto, nuevos adherentes a esa ideología. Por otra parte, y en vista de que la educación se ha convertido en un negocio muy lucrativo, pululan, en la actualidad, universidades privadas cuya misión también es graduar potenciales candidatos a ser contratados por los empleadores. En ese sentido, ser poseedor de un título universitario es condición sine qua non para aspirar a un puesto bien remunerado en la sociedad actual y, por ende, un mecanismo de exclusión (Juarros, 2005).

\section{Un nuevo paradigma en ciernes: de la uni-versidad a la multi-diversidad como foro de globalización no-hegemónica}

De los modelos de universidad expuestos anteriormente, en la actualidad priva el neoliberal. Esto, sin duda, tiene contentos a unos académicos e inconformes a otros, todo 
depende de su modo de entender el objeto y la función de la universidad, según la cosmovisión de cada cual. Lo que sí parece probable es que, de continuar la tendencia mercantilista de la globalización hegemónica, la universidad tradicional, tal y como la conocemos hoy, dejará de existir en cuestión de algunos años. Las razones para esta aseveración se ilustran en palabras de Ordorika (2006):

La crisis fiscal de las instituciones universitarias ha ido aparejada - a un mismo tiempo como causa y como consecuencia - a una redefinición del sentido, los fines y las prácticas de la educación superior. Las nociones de la universidad como proyecto cultural e institución productora de bienes públicos han pasado a un plano marginal o sólo discursivo (Marginson, 1997; Readings, 1996). Estas nociones han sido sustituidas por un énfasis renovado en la vinculación entre educación superior y mercados (Marginson, 1997; Marginson y Considine, 2000; Slaughter y Leslie, 1997), por un esquema de universidad "emprendedora" (Clark, 1998), por la noción de excelencia (Readings, 1996) y por un proceso creciente de privatización de la oferta educativa y del financiamiento (Slaughter y Leslie, 1997). (p. 37)

Ante este panorama, un nuevo modelo de universidad se encuentra en ciernes: El paso del concepto de uni-versidad, es decir, de universidad entendida como institución alineada con los intereses de los poderes que financian su sostenimiento o con los potenciales empleadores de sus graduados, al concepto de multi-diversidad, o sea, la universidad entendida como un foro de globalización no- hegemónica. En el presente trabajo se busca destacar la aparición de esa manera emergente de ser y hacer universidad.

No se trata de un intento por suprimir del todo el paradigma imperante. Tampoco se busca promover una actitud anarquista y de-sistematizadora de la institución universitaria. Lo que se persigue es aunar y recopilar los anhelos de la gente común, entre la que se encuentran los mismos estudiantes universitarios y la ciudadanía, en general, de que se logre incidir en un nuevo sentido común (Santos, 2003), de modo que la producción del conocimiento y las aplicaciones prácticas de este sirvan para unir a la sociedad en vez de segregarla y dividirla. Mediante la voluntad de los académicos por conformar una estructura alternativa de hacer universidad, utilizando los recursos tecnológicos para plantear, contextualizar y discutir acerca de los conocimientos que se producen, se puede llegar a sectores cada vez más amplios de la sociedad, en un modo no mercantilista y sí democrático de compartir el saber.

La gente de hoy ha llegado a la convicción de que el orden económico vigente es injustificable (Ordorika, 2006). Ahora se sabe que el género humano cuenta con los conocimientos suficientes para proporcionar medios de vida dignos para todos los habitantes del planeta. La gente también está empezando a comprender que, en el paradigma neoliberal dominante, la sostenibilidad de la actual economía de mercado depende de la escasez como mecanismo 
URL: http://www.una.ac.cr/educare

CORREO: educare@una.cr

regulador de la oferta y la demanda, de modo que, para mantener los precios de los productos y que las ganancias de las multinacionales se mantengan en crecimiento, se imponen políticas de control de la oferta, con lo que se sacrifica a los sectores con poco poder adquisitivo (Romero, 2009). El modelo de universidad imperante, en el que han desembocado sus antecesores, contemporiza con ese juego y coquetea con los impulsores de tales ideologías, que pretenden hacer creer al ciudadano común que ese es el único mundo posible, cuando en verdad, no lo es.

Por ello, así como ha habido quienes declaren que otro mundo es posible, es el momento de mirar de manera específica al ámbito académico e investigativo y proclamar también que otra universidad es posible. La manera de convertir en realidad lo que se atisba como una aspiración o, a lo más, como una iniciativa en estado incipiente es comenzar por la consecución de acuerdos de intersubjetividad (Leicester, 2000) entre los distintos sectores de generación y difusión del conocimiento, que estén dispuestos a emanciparse de los compromisos con instancias patrocinadoras, de manera que se logre crear un foro mundial que globalice el saber en sus distintas manifestaciones. Un foro que no limite ni condicione el acceso al conocimiento ni la posibilidad de hacer aportes, críticas o propuestas de ángulos de consideración alternativos a lo que se propone de ordinario.

Las herramientas tecnológicas que se encuentran a disposición del público como la red de internet $y$, dentro de ella, las redes sociales deberán convertirse en el gran recinto de enseñanza y aprendizaje para las generaciones del nuevo siglo, como lo afirman Valerio-Ureña y Valenzuela-González (2011):

Aunque para muchas personas la participación en las redes sociales les puede parecer una pérdida de tiempo, es probable que con ayuda de los profesores, estas herramientas ayuden a preparar mejor a los estudiantes universitarios para desempeñarse en la sociedad basada en conocimiento. Una sociedad donde la información debe fluir como la sangre, siendo las redes sociales sus venas. ... (p. 670)

La cátedra, entendida como autoridad para compartir conocimientos sustentados y con rigor científico deberá partir del acervo cultural con que cuenta la humanidad y de los nuevos hallazgos de la ciencia, que en el momento presente se encuentran sistematizados y regidos por la universidad tradicional. Debe salir de las aulas y de los círculos privilegiados de estudio hasta el alcance del individuo común, el cual representa la mayoría en toda sociedad. Este individuo común tendrá la tarea de realizar un proceso hermenéutico de esos saberes que recibe para analizar, desde su ubicuidad y desde su coyuntura histórica y social, las consecuencias potencialmente positivas o negativas para sí y para su entorno.

En el ínterin, es decir, desde que el saber emana de las fuentes de producción del conocimiento hasta el momento en que alcanza a la gente común, se requiere de un proceso de adaptación del lenguaje para que la jerga especializada llegue a los ciudadanos comunes 
en términos inteligibles para ellos (Valerio-Ureña y Valenzuela-González, 2011). Este será un trabajo muy delicado, pues requiere de un entrenamiento de la gente en el análisis del discurso para que aprendan a distinguir los marcadores discursivos que les intentan persuadir para que interpreten los mensajes en un determinado sentido.

Pero, así como algunos grupos de poder económico están interesados en que el grueso del público no pase del nivel del entretenimiento y el consumo en el enorme potencial que ofrece la red de internet, los académicos responsables del compromiso social que deriva de las oportunidades que ellos mismos en su momento recibieron deberán hacerse presentes en este foro público y libre de ataduras para colaborar con el proceso de formación permanente del público. Los expertos en lingüística aplicada, sobre todo desde el análisis crítico del discurso, pueden contribuir en gran medida, como lo afirma Van Dijk (2001), citado por Seidlhofer (2003):

El análisis crítico del discurso es un tipo de investigación analítica del discurso que, en principio, estudia la manera en que el abuso del poder social, la dominación y la desigualdad son perpetrados, reproducidos por el texto escrito y hablado en el contexto social y político. Con tal investigación disidente, los analistas críticos del discurso asumen una posición explícita, y así quieren entender, exponer y, en definitiva, resistir la desigualdad social. (p. 126)

La universidad, así transformada en multi-diversidad, como foro de globalización del saber proporcionará un espacio para que las propuestas de conocimiento que se divulguen puedan ser comentadas desde distintas perspectivas, de modo que la gente común derive sus propias conclusiones.

El objetivo es que la opinión pública sea una opinión madurada, sopesada y apropiada por la ciudadanía, en una pluralidad de perspectivas que incluso le den mayor validez a los mecanismos de consulta popular establecidos. Es decir, que si las sociedades del siglo XXI desean seguir apostando por la democracia como la mejor entre las formas de gobierno conocidas, deberá incentivar la madurez ciudadana y atender, sin subestimaciones, los pareceres que exprese la gente.

Si se acepta que los paradigmas del siglo XXI que describe Moncada (2008), citados en el segundo párrafo de este apartado, son verosímiles, la transformación de la universidad se constituye en un requisito de primer orden. Veamos:

3 Traducción del autor. El texto original dice: "Critical Discourse analysis (CDA) is a type of discourse analytical research that primarily studies the way social power abuse, dominance and inequality are enacted, reproduced and resisted by text and talk in the social and political context. With such dissident research, critical discourse analysts take explicit position, and thus want to understand, expose, and ultimately to resist social inequality". 
URL: http://www.una.ac.cr/educare

CORREO: educare@una.cr

Primero: Para que el desarrollo humano sea sustentable se deben variar las relaciones de producción actuales en las que cada individuo se desarrolla según sus posibilidades, con total independencia de lo que ocurra con los demás. Ese pretendido desarrollo humano es cualquier cosa menos sustentable. La brecha social que existe hoy generará, a la larga, un descontento social que hará insostenible incluso el estatus de bienestar de los sectores privilegiados. El nuevo modelo de universidad como foro de globalización no hegemónica deberá sugerir iniciativas de emprendedurismo para que, quienes poseen el recurso económico, inviertan en la creación de empleos en las comunidades $y$, sobre todo, en la seguridad alimentaria de los pueblos. No cabe duda de que existe talento y creatividad entre los académicos y profesionales educados para difundir esto de manera convincente y atractiva.

Segundo: La cultura de paz solo será posible cuando exista justicia cultural, es decir, cuando se practique con eficacia el ejercicio para que cada grupo cultural realice su propia obra hermenéutica de los mensajes que recibe y su propia autocrítica, a la luz de las otras culturas. Esto es un contrapeso a la enorme inversión que realizan los grupos de poder económico en los medios de información para pretender homogenizar las diversas culturas en torno a determinados hábitos de consumo. La universidad transformada y transformadora podrá usar los recursos gratuitos de la red para incentivar, en los individuos, la sana dialéctica entre la mismidad y la otredad.

Tercero: La educación permanente es un concepto que, en alguna medida, pone a todos los seres humanos bajo un denominador común: todos tienen necesidad de aprender. Una de las actitudes que más daño le han hecho a la humanidad es la pretensión de la gente educada e intelectual de ser autosuficiente y de desdeñar la sabiduría que se manifiesta en condiciones alternativas a las de la sociedades hegemónicas. Por esa actitud, la sociedad mundial se ha perdido de muchas riquezas en todo sentido, pero más que nada, en la riqueza de la interculturalidad, de la calidad de vida y de la armonía con el entorno. Un foro educativo mundial, gratuito, basado en la buena voluntad tiene el potencial de acercar a los seres humanos en un acto de re-conocimiento de sí mismos y de los demás.

En otras palabras, la universidad del futuro necesitará salirse de las aulas universitarias y requerirá que los intelectuales y especialistas de las diversas disciplinas dejen un tanto de lado la persecución de sus intereses individuales y trabajen por el bien común. Si no lo hacen por razones solidarias o filantrópicas, deberán hacerlo, cuando menos, por la sostenibilidad misma de la sociedad humana. Vista de esta forma, la universidad-multi-diversidad, lejos de estar en decadencia, se encuentra, más bien, apenas en sus albores y tiene ante sí un futuro muy promisorio al que debe abrazar con tanta más ilusión que la que deben de haber tenido los precursores de los distintos modelos de universidad en cada uno de sus estados anteriores. Gracias a ellos, el género humano ha alcanzado saberes para superar pestes, calamidades, conflictos y muchas otras vicisitudes; de igual modo ha alcanzado logros que lo dignifican y le proporcionan confort. A esto es y seguirá siendo llamado, mientras exista. 


\section{Conclusiones}

Las conclusiones que se derivan de la anterior disertación se pueden exponer en dos vertientes.

La primera vertiente que conviene resaltar es la integración del conocimiento, como el gran reto que deberá afrontar el paradigma universitario emergente. En la actualidad, las redes sociales muestran cómo la juventud se encuentra ávida de saber y de desenmascarar las fuentes informativas y publicitarias que sirven a diversos intereses de manipulación y de alienación. Por fortuna, la tecnología del futuro se encargará de proporcionar nuevas e ingeniosas maneras de conectar las mentes y las conciencias en torno a esa preocupación. Ciertamente, hoy la juventud comparte ese interés con el coqueteo del consumo y la trivialidad. Es probable, sin embargo, que la síntesis de esas realidades concomitantes provenga del hastío. Ya algunas sociedades desarrolladas lo están experimentando en su población joven. Pero, lejos de significar pura fatalidad, el hastío puede provocar, más bien, nuevas revoluciones psicológicas que devengan cosmovisiones saludables y propositivas.

La primera de esas revoluciones es, sin duda, el sentimiento de indignación (Hessel, 2010), el cual les demandará un cambio, en sí mismos y en la sociedad total, hacia una vida con mayor responsabilidad. Fruto de esa indignación, la gente desarrollará -como segunda revoluciónun nuevo sentido común, que habrá de ser, a la vez, crítico y solidario (Santos, 2003): crítico, para acrisolar, según su propia realidad, los significantes que se les presenten; solidario, para reconocer en los demás a sujetos que comparten la misma condición y, además, que la suerte de cada cual depende, de modo irremediable, de las demás personas.

Esas dos revoluciones, la indignación y el nuevo sentido común, permitirán que el conocimiento, tanto el que se posee como el que se produzca, sea integrado de manera prudente y crítica y, por la magia de las tecnologías de la información, alcance a todos los sectores sociales.

La segunda vertiente es la definición de cuál ha de ser el cometido de esa integración del conocimiento, dentro del nuevo paradigma. En este caso, se apunta a la libertad del ser humano para la búsqueda del bien común. El conocimiento, depurado críticamente y compartido con la gente común, será la herramienta primordial de emancipación. Gracias a él, el pueblo logrará una capacidad de discernimiento y de resistencia para prevenirse y para liberarse de los colonialismos del presente, así como de los del pasado. Como resultado, emergerán propuestas alternativas de todo tipo para el modo de producción y para las relaciones humanas. Esa será la nueva universidad: una universidad en poder de la gente, de las comunidades, no limitada por la institucionalidad ni por las fuentes de financiamiento, sino fruto de una voluntad irrefrenable del ser humano por reivindicar su papel en la naturaleza, un papel que esté a la altura de su capacidad. En ese sentido, el personal académico de hoy es el primero que requiere emancipación.

La visión de universidad que se ha intentado proponer aquí no busca desplazar el modelo tradicional imperante. Este, como se dijo, continuará en boga durante un buen 
URL: http://www.una.ac.cr/educare

CORREO: educare@una.cr

tiempo y, eventualmente, cuando el orden económico impuesto por el capitalismo económico financiero haya agotado la mayor parte de los recursos de la naturaleza y haya convertido en inaprovechable la otra parte, el modelo de universidad que conocemos hoy necesitará de una modificación ostensible.

\section{Referencias}

Campillo, M. y Sáez J. (marzo, 2013). La universidad desde sus imágenes. Profesionalización, desprofesionalización o proletarización en la universidad contemporánea. Athenea Digital 13(1), 121-137. Recuperado de https://docs.google.com/viewer?url=http://www.redalyc.org/ pdf/537/53725662009.pdf\&chrome=true

Dale, R. y Robertson, S. (enero, 2004). Interview with Boaventura de Sousa Santos [Entrevista con Boaventura de Sousa Santos]. Globalization, Societies and Education. 2(2), 1-22. Recuperado de http://www.boaventuradesousasantos.pt/documentos/boainterview1.pdf

Ema, J. E., García, J., Arribas, S. y Cano, G. (2013) ¿Qué (nos) está pasando en la universidad? Athenea Digital, 13(1), 3-6. Recuperado de http://psicologiasocial.uab.es/athenea/index. php/atheneaDigital/article/view/1173-Ema/pdf

Gilson, E. (1965). La filosofía en la Edad Media. Desde los orígenes patrióticos hasta el fin del siglo XIV. Madrid: Gredos.

Gómez, M. I. (2008). El TLC es inconstitucional por legitimar la biopiratería en contra del interés nacional. OASIS. Observatorio de Análisis de los Sistemas Internacionales, 13, 115-143. Recuperado de http://www.redalyc.org/pdf/531/53113141006.pdf

Haba, E.. P. (2002). El desafío (contraacadémico) de las universidades privadas en Costa Rica. Buenos negocios, facilismo/aprobismo, acreditación y algunas floraciones concomitantes. Revista de Ciencias Sociales, 3(97), 79-93. Recuperado de http://163.178.170.74/wp-content/ revistas/97/06-HABA 79-93.pdf

Hessel, S. (2010). Indignaos! Recuperado de http://xa.yimg.com/kq/groups/15376333/1183605981/ name/\%C2\%A1INDIGNAOS!.pdf

Jaramillo, C. M. (enero-junio, 2011). Posibilidades y límites de la universidad latinoamericana desde una perspectiva histórica. El Ágora USB, 11(1), 153-171. Recuperado de http://dialnet. unirioja.es/servlet/articulo?codigo $=4136944$

Juarros, M. (mayo-junio, 2005). Nuevos patrones en la producción de conocimiento. Los efectos de la vinculación entre los principios del mercado y los valores académicos. Revista argentina de sociología, 3(4), 117-132. Recuperado de https://docs.google.com/viewer?url=http:// www.redalyc.org/pdf/269/26930407.pdf\&chrome=true 
Leicester, M. (enero-febrero, 2000). Post-Postmodernism and Continuing Education [El postmodernismo y la educación continua]. International Journal of Lifelong Education, 19(1), 73-81.

Lenaers, R. (2006). Otro cristianismo es posible. Recuperado de http://2006.atrio.org/?page $\underline{i d=1616}$

Marín, L. (agosto, 2006). Otra psicología es posible. Psicología sin fronteras: Revista electrónica de intervención psicosocial y psicología comunitaria, 1(2), 15-25. Recuperado de http://dialnet. unirioja.es/servlet/articulo?codigo $=2652422$

Marín, L. F. (enero-junio, 2007). La noción de paradigma. Signo y pensamiento, 26(50), 34-45. Recuperado de http://www.scielo.org.co/pdf/signo/n50/n50a04.pdf

Mejía, A. (2008). La utopía no ha muerto. Abogado, 50 años: El orgullo de ser. México: Jitanjáfora Morelia Editorial. Recuperado de http://books.google.es/books?id=0R-GKbiCQJIC\&printse $\mathrm{c}=$ frontcover $\& \mathrm{hl}=\mathrm{es} \&$ source=gbs ge summary $\mathrm{r} \& \mathrm{cad}=0 \# \mathrm{v}=$ onepage \&q\&f=false

Mejía, O. y Jiménez, C. (julio-diciembre, 2005). Nuevas teorías de la democracia: De la democracia formal a la democracia deliberativa. Colombia Internacional, 62, 12-31. Recuperado de http://colombiainternacional.uniandes.edu.co/view.php/464/view.php

Moncada, J. S. (agosto, 2008). La universidad: Un acercamiento histórico-filosófico. Ideas y Valores, 57(137), 131-148. Recuperado de https://docs.google.com/viewer?url=http://www.redalyc. org/pdf/809/80915459008.pdf\&chrome=true

Newman, J. H. (2007). Discourse 5. Knowledge its Own End [Discurso 5: El conocimiento, un fin en sí mismo]. Disponible en http://www.newmanreader.org/works/idea/discourse5.html

Ordorika, I. (diciembre, 2006). Educación superior y globalización: Las universidades públicas frente a la nueva hegemonía. Andamios, 3(5), 31-47. Recuperado de http://www.ses.unam. $\mathrm{mx} /$ curso2007/pdf/OrdorikaEnAndamios.pdf

Otra televisión es posible (noviembre-diciembre, 2010). Nuestro Tiempo, 665, 6-7. Recuperado de http://www.unav.es/nuestrotiempo/es/temas/otra-television-es-posible

Paravicino, E. R. (2003). [Revisión del libro Kloaka. 20 años después. MK (1982-1984): Cultura juvenil urbana de la postmodernidad periférica, por J. Zevallos]. Revista de crítica literaria latinoamericana, 29(57), 276-279. Recuperado de http://ase.tufts.edu/romlang/rcll/ pdfs/57/57resenas8.pdf

Pérez, A. J. (2010). Rodolfo Kusch y su crítica a la razón occidental. Mitológicas, 25, 27-38. Recuperado de http://www.redalyc.org/pdf/146/14615247002.pdf 
URL: http://www.una.ac.cr/educare

CORREO: educare@una.cr

Romero, E. (enero-marzo, 2009). [Revisión del libro El estado de la inseguridad alimentaria en el mundo / Los precios elevados de los alimentos y la seguridad alimentaria: Amenazas y oportunidades, por FAO]. Problemas del Desarrollo. Revista latinoamericana de economía, 40(156), 221-225. Recuperado de https://docs.google.com/viewer?url=http://www.redalyc. org/pdf/118/11820096011.pdf\&chrome=true

Santos, B. (2003). Crítica de la razón indolente. Contra el desperdicio de la experiencia (Vol. 1, Crítica de la razón indolente: Contra el desperdicio de la experiencia). Bilbao: Desclée de Brouwer.

Segarra, J. A. (2011). La Fageda: Otra empresa es posible... Universia Business Review, 30, 110-119. Recuperado de https://docs.google.com/viewer?url=http://www.redalyc.org/ pdf/433/43318798009.pdf\&chrome=true

Seidlhofer, B. (Editor). (2003). Controversies in Applied Linguistics [Controversias en lingüistica aplicada]. Oxford: Oxford University Press.

Valerio-Ureña, G. y Valenzuela-González, R. (noviembre-diciembre, 2011). Redes sociales y estudiantes universitarios: Del nativo digital al informívoro saludable. El profesional de la información, 20(6), 667-670. Recuperado de http://www.academia.edu/1319067/REDES SOCIALES Y ESTUDIANTES UNIVERSITARIOS DEL NATIVO DIGITAL AL INFORMIVORO SALUDABLE

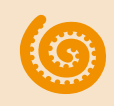

\section{Cómo citar este artículo en APA:}

Barrantes, L. G. (2013). Otra universidad es posible. Revista Electrónica Educare, 17(3), 7-20. Recuperado de

http://www.revistas.una.ac.cr/index.php/EDUCARE/issue/current

Nota: Para citar este artículo en otros sistemas puede consultar el hipervínculo "Como citar el artículo" en la barra derecha de nuestro sitio web:

http://www.revistas.una.ac.cr/index.php/EDUCARE/index 